\title{
INDIAN AUTOMOBILE INDUSTRY: POST-COVID CHALLENGES AND STRATEGIES
}

\author{
${ }^{1}$ Punita Duhan, ${ }^{* 2}$ Adya Rajpal, ${ }^{3}$ Prithvi Raj Agrawal \\ ${ }^{1}$ Meera Bai Institute of Technology, Department of Training and Technical Education, \\ Govt. of NCT of Delhi New Delhi- 110065 \\ ${ }^{2}$ The Shri Ram School, Moulsari, Gurugram, Haryana - 122002. \\ ${ }^{3}$ Delhi Public School International, New Delhi, Delhi - 110049 \\ *Corresponding Author
}

DOI: 10.46609/IJSSER.2020.v05i07.006 URL: https://doi.org/10.46609/IJSSER.2020.v05i07.006

\begin{abstract}
As the economies around the world are severely affected by the surge of dominant COVID-19 pandemic, Indian economy is also set to undergo an irrevocable hemorrhage. Although the prodigious changes in demand and supply activities are sure to have gargantuan impact on innumerable industries, one industry in the forefront of this impact is the automobile industry. Indian automobile industry, with its worst ever half-yearly performance from April - September 2019 as the passenger vehicle segment saw an overall decline of $23.56 \%$, had been grappling with a major slowdown even before the COVID-19 crisis hit Indian markets. Outburst of COVID-19, subsequent lockdowns, reduced economic activities, reduced income, loss of jobs, labour migration etc. have further strained the industry. Accordingly, the present paper is a sincere attempt by the researchers to explore the impact of these changes on Indian automobile sector with specific reference to the passenger vehicle segment. Paper, using credible secondary data, analyzes present conditions to understand various issues, challenges, hurdles and future prospects of four-wheel passenger vehicles in India while suggesting appropriate revitalization strategies to boost the sales.
\end{abstract}

Keywords: Indian Automobile Industry, COVID-19, Revitalization strategies, Passenger Vehicle Segment. 


\section{INTRODUCTION}

Indian automobile industry, presently the fourth largest in the world, contributes approximately 7\% of Gross Domestic Product and 22\% of Manufacturing Gross Domestic Product of India, therefore establishing its predominance in driving economic growth. Hegemonized by Two Wheelers segment with $81 \%$ of market share, and Passenger Vehicles segment with $13 \%$ of market share (according to Domestic Market Share Statistics of 2019-2020 and depicted in figure 1), Indian automobile industry reflects the primary characteristics of Indian population - young and middle class; and therefore the primary characteristics of their demand.

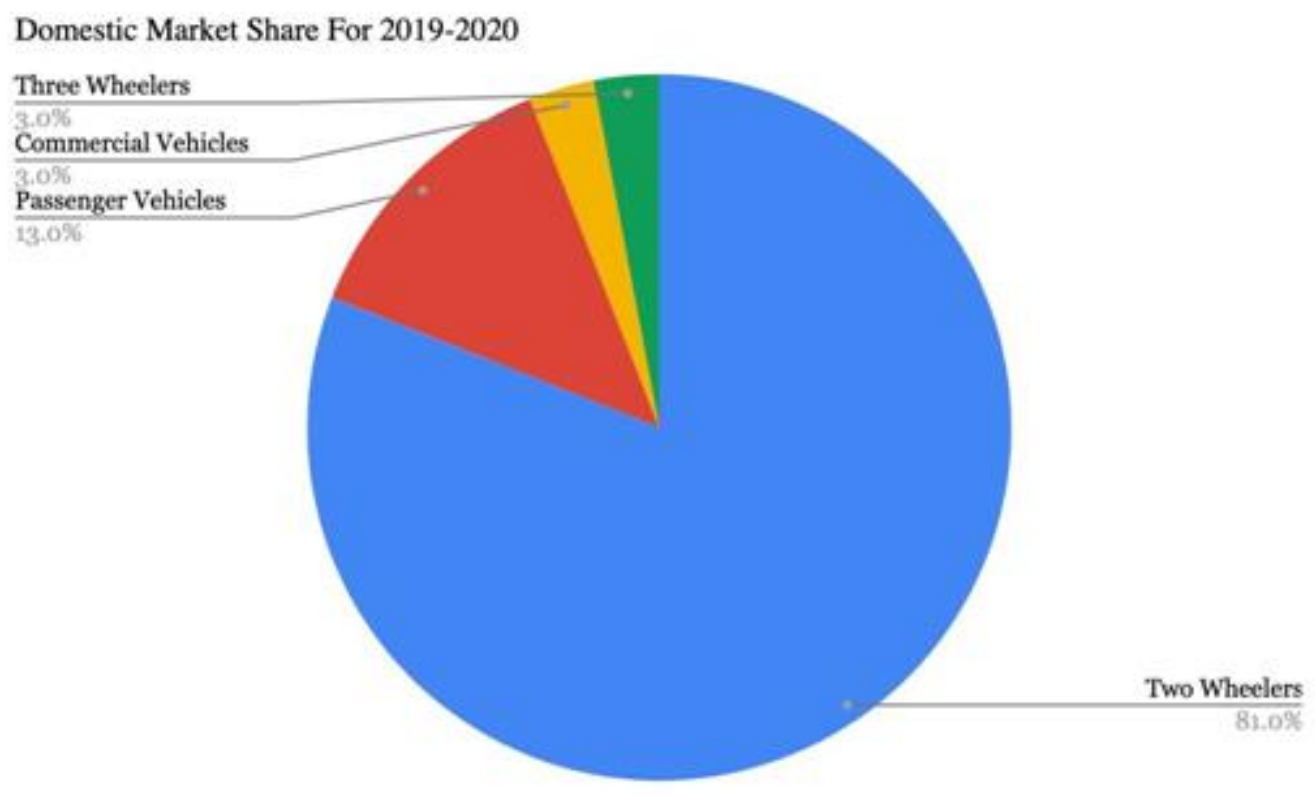

Figure 1: Domestic Market Share for 2019-2020

Source: Adapted from Society of Indian Automobile Manufacturers (SIAM) statistics

This demand was manifested in the average annual production of 29 million, according to data from Society of Indian Automobile Manufacturers (SIAM), of this sector of Indian economy up until 2018, on account of its traditional ascendancy in casting, forging, precision machining, fabricating, labour costs, foreign direct investment (FDI) inflows, and ability to match the nature and quantum of the aggregate consumer demand. However, over the last two years, an amalgamation of a reported economic slowdown, liquidity crunch, introduction of Bharat StageVI norms, and United States - China Trade war resulted in the deceleration of this growing industry to the output of Fiscal Year 2016 (FY16) as depicted by figure 2. Whereas on one hand, Bharat Stage VI emission norms resulted in increased production costs which transcended into 
increased market prices, simultaneous abatement of GDP to $4.7 \%$ due to contraction in manufacturing sector output, depreciation of rupee as a ramification of the United States - China Trade war, and retrenchment of credit to private corporate sector owing to heightened risk aversion in banking system furthered the disruption of demand in automobile sector.

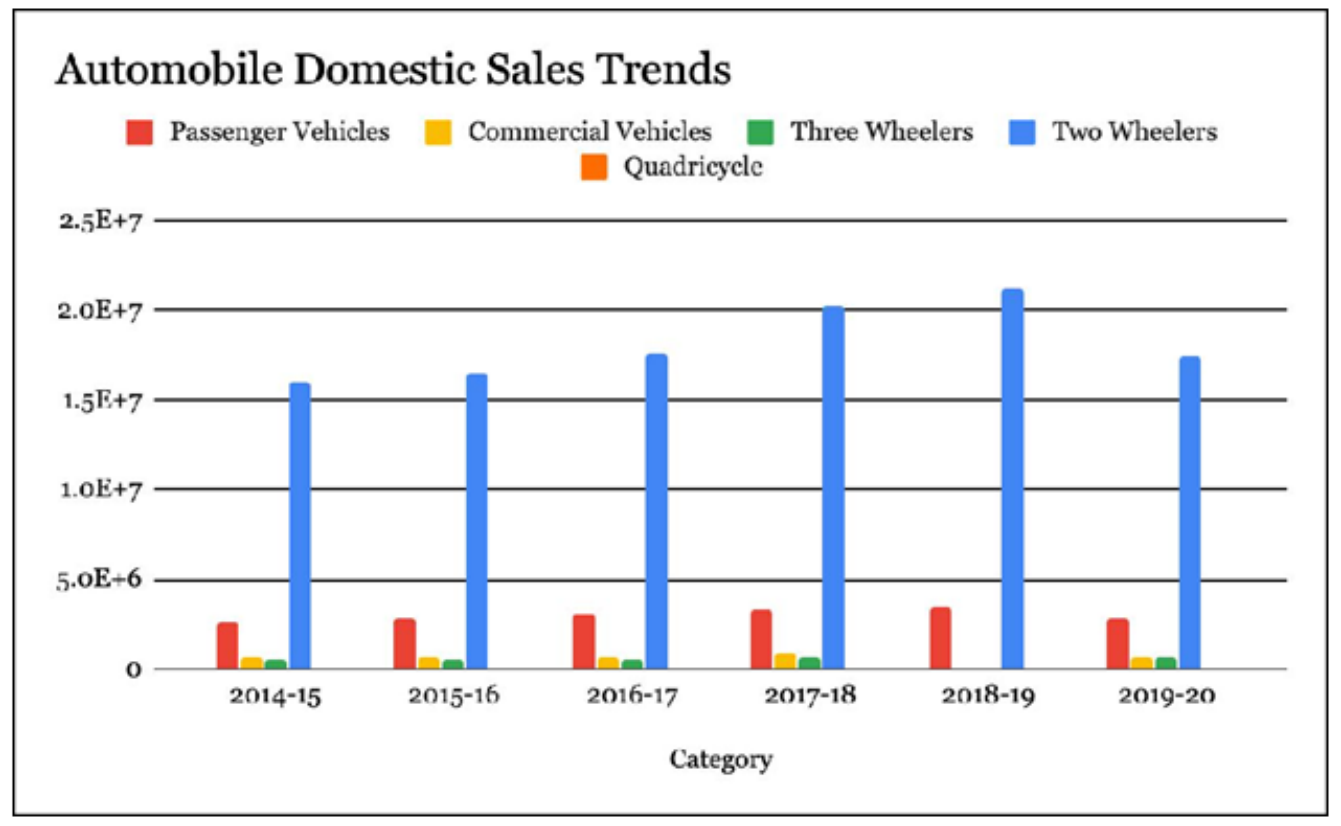

Figure 2: Automobile Domestic Sales Trends

Source: Adapted from Society of Indian Automobile Manufacturers (SIAM) statistics

This embryonic disruption to the economy and therefore the automobile industry which proceeds in parallel, however, was merely the trigger to the worst economic recession since the Great Depression in 1930's, due to proliferation of Covid-19 Pandemic. India recorded its first positive case of Covid-19 on 30th January, 2020. Since then, we have been spectators to an exponential surge of transmission as the cases reach an approximation of 3 lakh. Consequently, 24th March 2020 demarcated the implementation of first lockdown in India, which was followed by five extended lockdowns, up until 31st May, 2020. As all non-essential services and businesses, retail establishments, educational institutions, places of religious worship, public utilities and government offices across the country remained under absolute shutdown, the Indian economy further descended into adversity. Heightened unemployment as millions of jobs and livelihoods lie in uncertainty, restricted transportation of raw materials and finished goods and stagnant trade and commerce as a result of sealed domestic and international borders have concurrently engendered distorted production operations and distribution chains. Therefore, when the near- 


\section{International Journal of Social Science and Economic Research}

ISSN: $2455-8834$

Volume: 05, Issue: 07 "July 2020"

stagnant automobile industry was hit with this economic upheaval - the adjunction of an impaired supply mechanism to an existant demand shock - it reached a complete standstill, recording a total of zero sales for all vehicle segments in April 2020, followed by a meager 36000 in sales in May 2020, according to reports by the Automotive Component Manufacturers Association of India (Mukhtyar \& Chatterjee, 2020) - the lowest recorded figures India has ever been privy to. Of this, one pre-eminent segment to endure the aforementioned tribulation acutely is Passenger Vehicle segment.

Hence, this paper attempts to anatomize the plausible challenges being faced by Indian automobile industry and offers future approaches to revitalize this industry to its past opulence. To achieve these objectives, researchers employ exploratory research design. Study is based on an in-depth study and documentary analysis of secondary data available at accessible online sources in the form of newspapers and annual credit reports by acclaimed agencies. Thus, the study derives its merits from a comprehensive statistical and predicted trends anatomization through three sections. Section I and II of the paper analyse the implications of changes in the demand and supply, as suggested by available and accessible literature, to the Passenger Vehicle segment after giving a brief overview of the Indian Passenger Vehicle segment. Section III concludes suggestions for discrete future measures and the next section details limitations, future research directions and conclusions.

\section{Overview of Indian Passenger Vehicle Sector}

The Indian Passenger Vehicle Segment, comprising over 2 million vehicles therefore reflecting the most diverse segment of the automobile industry, has suffered a decline of more than $51 \%$ in overall sales by mid-March just after the initial 21 day Lockdown period. As per data released by Society of Indian Automobile Manufacturers (SIAM), Passenger vehicle sales plummeted to a record low of 1,43,014 units in March 2020, which compared with the 2,91,861 units sold in March 2019, constitutes a sharp 51\% plunge. The sheer magnitude of this crisis and its acute nature especially on Passenger Vehicle Segment is clearly illustrated in view of the synchronous demand and supply-side shock, this sector has been hit with.

\section{Demand Shock faced by Passenger Vehicle Industry}

\section{Consumer Behavioral Changes}

Constituting the most diverse segment of the Automobile Industry, inordinately preferred by the middle-class, as well as tranches of the lower-class and upper-class, the Passenger Vehicle Segment, according to Klynveld Peat Marwick Goerdeler's (KPMG) Report 'Potential Impact of Covid-19 on the Indian Economy', is the most heavily contingent upon 'market sentiments and 
consumer purchasing power'(Goerdeler, 2020). As a result, the facets of Covid-19, characterised by a momentous change in these sentiments and behavior, have posed copious challenges, particularly for the demand of this segment of the Automobile Industry.

\section{Consumer Confidence}

Consumer confidence - an economic measure of the degree of optimism about the economy or segments about the economy - is a definitive indicator of the consumer aggregate demand. According to The Reserve Bank of India's Consumer Confidence Survey May 2020, as depicted in Figure 3, consumer confidence of Indian citizens has seen an exponential decay as reflected by trend line, reaching an appalling low as of May 2020, reflecting that consumers are wary of the dire economic conditions prevailing in the economy, as a result of the uncertainty regarding Covid-19. Uncertainty has long been known to parallel low confidence, conducing to a relatively prudent attitude in consumers which insinuates a tendency to engage in self-insurance and saving- inherantly reducing the predisposition of purchases. Moreover, since the purchase of passenger vehicles, are relatively prodigious investments with approximately $2 / 3$ rd purchases involving loans (Coopers, 2020) - particularly for the lower and middle class who constitute the preponderance - low consumer confidence supplemented with credit constraints by banks, due to liquidity crunch and banking crisis, recorded by Rolend Berger's 2020 Report, hinders their demand, rendering a potent demand-shock, in accordance with the statistical data.

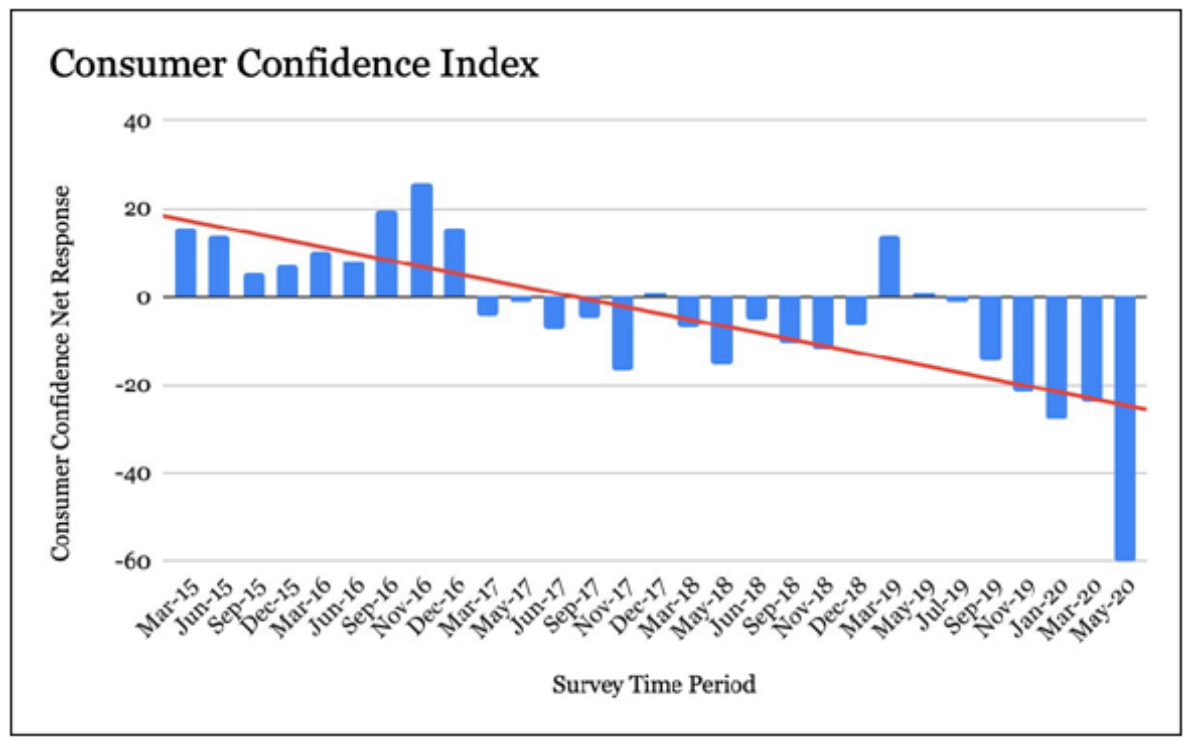

Figure 3: Consumer Confidence Index

Source: Adapted from Reserve Bank of India Consumer Confidence Survey May 2020 


\section{Altered Incomes and Purchasing Activity}

According to The Chicago Booth's Rustandy Center for Social Sector Innovation's data analysis of The Center for Monitoring Indian Economy's surveys covering about 5,800 homes across 27 Indian states from April, 2020, nearly 84\% of Indian households experienced a diminution in their incomes, under the stringent lockdown directives. According to the International Labour Organization at the United Nations ' 400 million people working in the informal economy in India are at risk of falling deeper into poverty due to the coronavirus crisis which is having "catastrophic consequences", and is expected to wipe out 195 million full-time jobs'. The aforementioned figures delineate the gargantuan loss of incomes and livelihoods as a product of Covid-19, resulting in conscious purchasing or a lower marginal propensity to consume consumers have sustained their spending on inelastic, essential goods and services, while cautiously avoiding procurement of discretionary, luxury goods, as reflected by Figure 4 and Figure 5. Passenger Vehicles as such fall under discretionary goods, pertaining solely to convenience instead of necessity (Collie, 2020), therefore the significant loss of income, augmented with limited availability of non-essential goods and service, has significantly reduced demand, and is forecasted to do so in the near future as well. A possible scenario however is that the mid-high segment of this passenger vehicles sector stabilises momentarily as the incomes of the higher-class consumers remain largely unsusceptible to the aforementioned adversities. The lower bound, and mid-segment of this sector, however will indubitably be belaboured by the approaching wave of low disposable incomes, aggravating the demand shock.

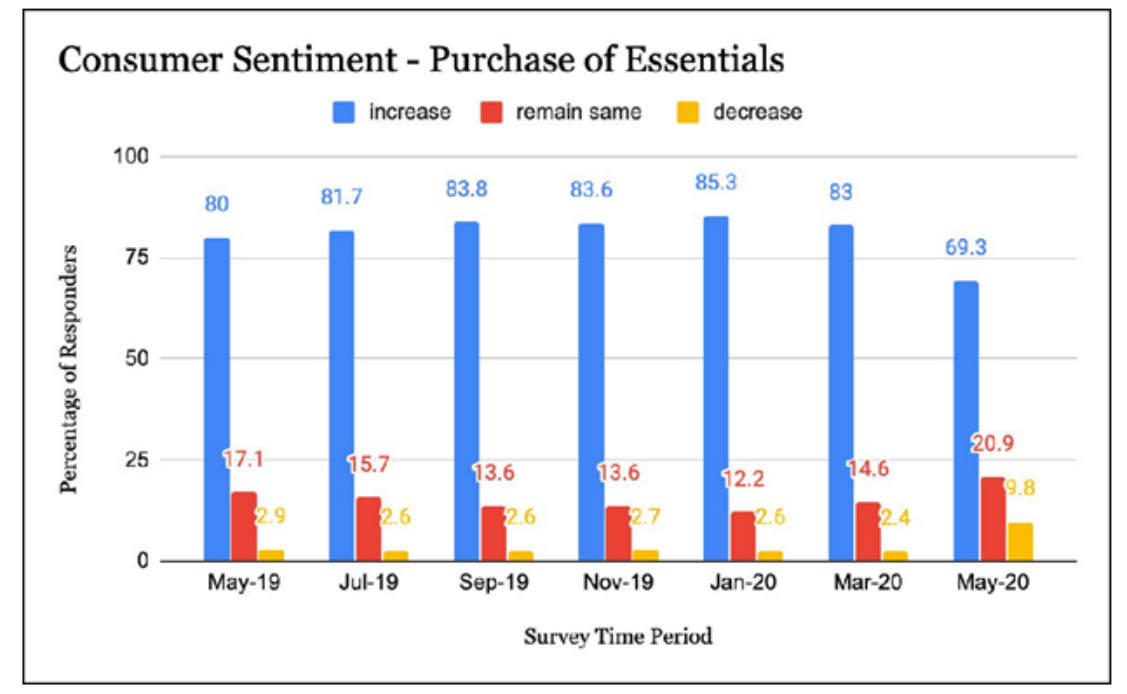

Figure 4: Consumer Sentiment - Purchase of Essentials

Source: Adapted from Reserve Bank of India Consumer Confidence Survey May 2020 


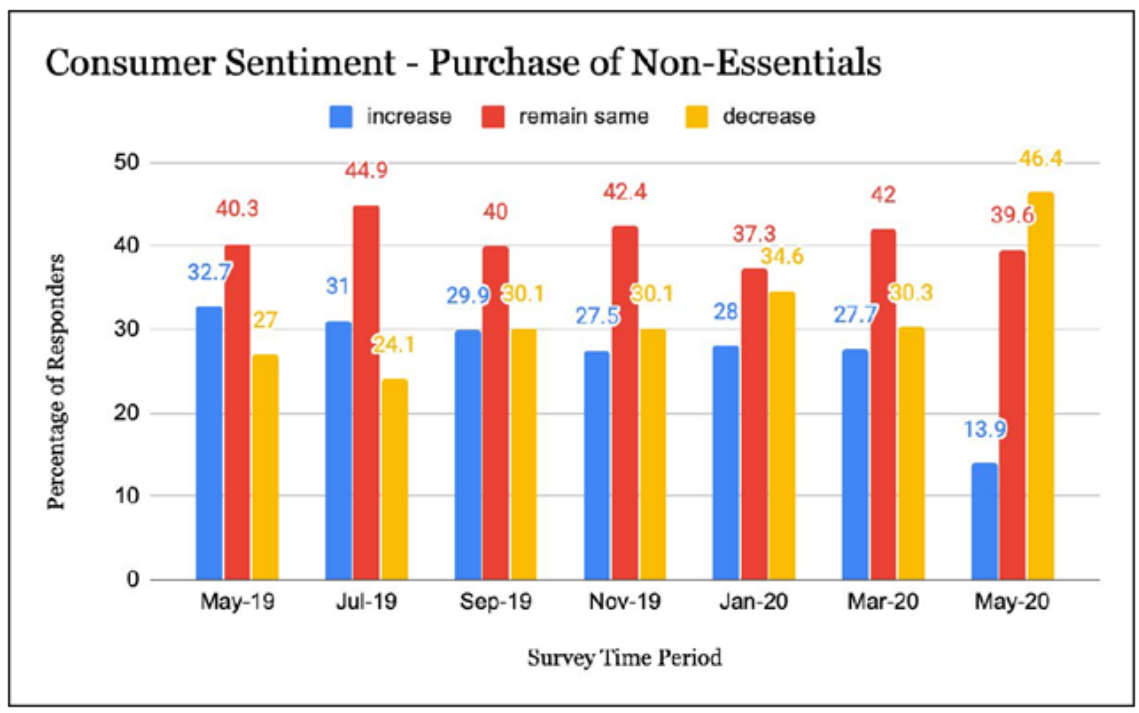

Figure 5: Consumer Sentiment - Purchase of Non-Essentials

Source: Adapted from Reserve Bank of India Consumer Confidence Survey May 2020

\section{Implications of lockdown}

\section{Physical Limitations and Digitization}

While the world braces itself to uplift the implemented restrictions on businesses and households, the ripples of the lasting lockdown will continue to have a lingering impact on consumer behaviour and attitude. The physical curtailment due to lockdown prevented any consumption of sizeable goods such as vehicles and further stipulated the adoption of a digitalized lifestyle (Accenture, 2020) - digital commerce in specific, the ease and allure of which has predicted it to be persistent. Consumers magnetizing towards this digital trend are less likely to visit dealerships due to paramount importance of health and hygiene, the foremost avenue for purchases, thus rendering a significant loss of demand ("Labour Day is typically meant to highlight...”, 2020). However, the more palpable obstacle lies in the embryonic condition of the digital passenger-vehicle marketplace, which if not developed efficiently will render an irreversible hemorrhage of unfulfilled demand.

\section{Exports}

While the domestic sales have been low due to negative market sentiments and BS6 transition, a comprehensive view of the automobile market suggests negative global demand as well, suggested primarily by the mammoth contraction of exports. According to Economic Times as of 
April 2020, Indian exports 'shrank by a record 60.28 per cent in April to $\$ 10.36$ billion' ("Contracting for the second straight...", 2020) resulting in the lowest trade deficit since 2016. Of this, the Indian automobile sector served to be one of the most severed industries, with exports vehicles and components - worth 9 Billion US Dollars to North America and Europe - its largest markets - stalled precariously (Sachs, 2020).

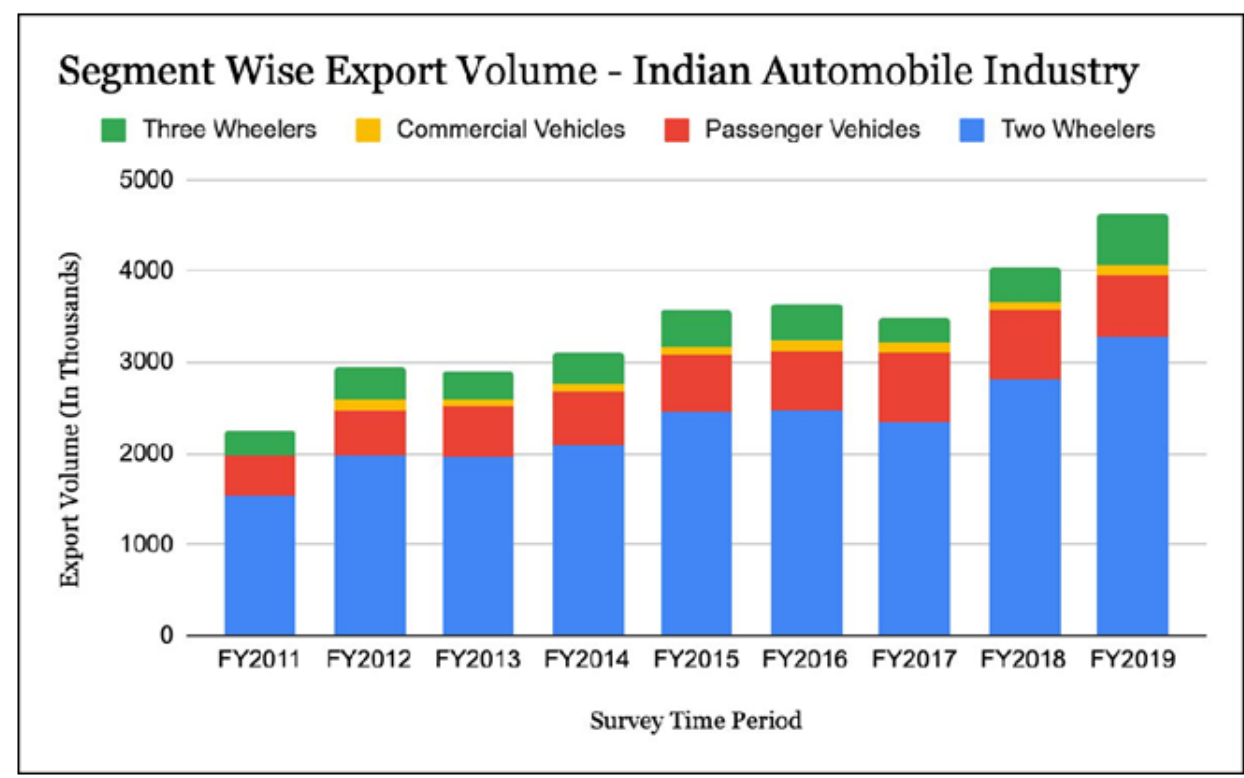

Figure 6: Segment Wise Export Volume

Source: Adapted from Statista export volume of automobiles from India from FY 2011 to FY 2019, by type

This shrinkage of demand can be attributed to the global slowdown, imposed trade restrictions due to occluded borders, and severity of lockdowns in all major export nations. Passenger Vehicles, as depicted in Figure 6 constitute a substantial weight of this loss, and according to reports by Automotive Component Manufacturers Association of India (ACMA), are in particular forecasted to experience 'a major downturn in automotive exports over the next few months'(Mukhtyar \& Chatterjee, 2020), reflecting the degree of global demand shock for this sector of Passenger vehicles.

Although opponents have suggested the possibility of an alternative scenario - feasible increase of demand of Passenger Vehicles owing to trepidation regarding the use of Public Transit - a widespread means of transportation in the developing country of India - due to perceived health and sanitation risks. However, the aforementioned scenario serves to implausible for it is highly 


\section{International Journal of Social Science and Economic Research}

ISSN: $2455-8834$

Volume: 05, Issue: 07 "July 2020"

unlikely that commuters of public transport, also the most inexpensive means of transportation, will be able to afford this shift to Passenger Vehicles, who's weighted average price is expected to amount to US\$23,792 in 2020 (Statista, May 2020), specifically given the reduced disposable incomes and constricted loans by banks and NBFCs. Therefore, a coalescence of the aforementioned factors - low consumer confidence, reduced incomes, altered purchasing sentiments, loss of exports and imposed lockdowns - indispensable determinants of the aggregate demand for an industry, promise a prodigious demand shock to the Passenger Vehicle Sector in the present, and the extended future.

\section{Supply Shock faced by Passenger Vehicle Industry}

Covid-19, declared the most significant epidemic in terms of economic pandemonium, has not only ensued the the most corpulent demand-shock to the Indian Automobile Industry in centuries but also rendered ripple effects in its supply chain for years to come. This claim can be substantiated by the Information and Credit Rating Agency's (ICRA) latest report, according to which 70 percent of the respondents have faced or are likely to face supply chain disruptions manifested in subsided production ("The supply-chain have encountered...", 2020), labour force challenges, loss of essential imports and monetary uncertainties.

\section{Implications of Lockdown}

\section{Collapse of Production}

The successive lockdowns implemented by the government to curtail exponential growth of positive cases resulted in a complete halt to all non-essential economic activity for the duration of the lockdowns. For the auto industry, this meant complete temporary shutdowns of all stages of manufacturing and production. As vehicle manufacturers including Maruti Suzuki, Hyundai, Kia, Honda, Toyota and others (Collie, 2020), across the country shut-down their production lines for over two months (Beredo, 2020), the Indian Automotive industry was forced to endure a loss of ₹2300 crore or more in revenues, on a daily basis, according to the Society of Indian Automobile Manufacturers (SIAM). This impact of this prodigious deficit, according to Autobei Consulting Group's (ACG) 'Indian Automobile Industry Report Q1 FY 2020 report', was most excessively bred by the Passenger Vehicle Segment. Still attempting to become habituated to the transmission of the Bharat Stage VI Emission norms, the protracted lockdowns have resulted in a 24\% (ACG, 2020) - the largest - decline in production for this Passenger Vehicle Sector, posing a significant obstacle to the revitalization of its supply, and therefore market in entirety.

\section{Labour Force/Employees Challenges}


A quintessential segment of supply chains is the workforce that drives it. Covid-19 however, gravely endangers the Indian automobile sector's workforce due to health considerations, employee sentiment and affordability. The revenue deficit due to lockdowns has posed magnified losses for automobile firms, who have subsequently had to contribute to the loss of '195 million jobs' - comprising the labour force of this sector as well. This inevitable unemployment supplemented with stringent healthcare precautions (Kumar, 2020) - primarily the prevalent idea of social distancing - preventing the simultaneous presence of the entire workforce, has resulted in a sizable labour shortage in Automobile therefore Passenger Vehicle sector. Additionally, as depicted by Figure 7, employee sentiment reflects an intrinsic preference of the 'Work-At-Home' notion (Accenture, 2020), promulgated profusely amidst months of lockdown. This shortage of physically available labour, furthers the supply side shock, challenging the resuscitation of this near-stagnant sector.

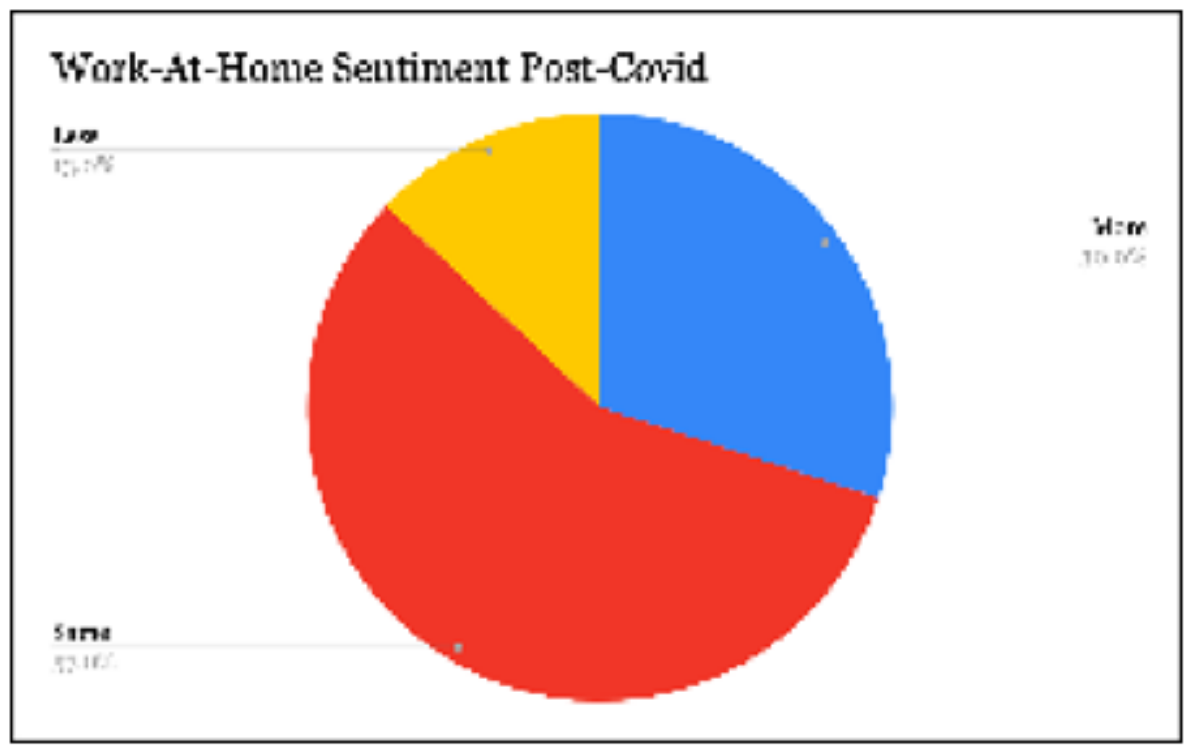

Figure 7: Work at Home Sentiment Post-Covid

Source: Accenture COVID-19 Consumer Research, conducted April 2-6, N = 1,118 respondents

\section{Imports}

According to Klynveld Peat Marwick Goerdeler's (KPMG) Report 'Potential Impact of Covid19 on the Indian Economy', China - the very pioneer of Covid-19 - accounts for $27 \%$ of India's automotive part imports and is home to several factories of prime global automotive part manufacturers such as Robert Bosch GmbH, Valeo AS and ZF Friedrichshafen AG(Goerdeler, 2020). However, due to mammoth burgeoning of Covid-19, bearing a similarity to India, these 
International Journal of Social Science and Economic Research

ISSN: $2455-8834$

Volume: 05, Issue: 07 "July 2020"

factories as well as international borders underwent and are currently undergoing prolonged closure. As a result, there has reportedly been severe uncertainty and delay in the production and delivery of requisite automotive parts of a variety of Passenger Vehicles from China in particular, but several other import markets as well, subsequently diminishing production of Passenger Vehicles for an extended, deleterious duration.

\section{Monetary Uncertainties}

\section{Price Fluctuations of Raw Materials}

The precarious uncertainty regarding the Covid-19 pandemic, has transcended into uncertainties in the global marketplace for raw materials including steel, iron-ore, met-coal and oil quintessential for the manufacturing of vehicles. The differing demand-side and supply-side trends amongst major producers of these raw materials, particularly India, China and Brazil is rendering volatile price fluctuations for them. Comparatively prolonged lockdowns in India - the largest seaborne consumer of met-coal - is resulting in a shrouded uncertain demand for it, lending to uncertain prices for it. On the other hand, several Brazilian iron-ore operations have collapsed amidst this pandemic, rendering a drastic fall in supply which may result in inflated prices for iron-ore. Moreover, China is reported to exhibit a persistant increased pellet consumption, taking advantage of 'low freight rates' (Brooks \& Sabet, 2020) further adding to capricious raw material prices, which reflects a posingly uncertain supply for passenger vehicle sector.

\section{Liquidity Crunch}

The last few years have presented a severe liquidity crisis to the Indian Market due to NonBanking Financial Companies (NBFCs) in particular, resulting in increased costs of borrowing due to increased business and consumer interest rates (Berger, 2020) and continues to plague Indian Industries during Covid-19 too. As the process of acquiring loans or credit continues to become more arduous, the Indian Automobile Industry, with a pre-existing severed revenue deficit is confronted with further obstacles to invest in the requisite factors of production machinery, raw materials, land, labour - required to revitalize its supply. According to Klynveld Peat Marwick Goerdeler's (KPMG) Report 'Potential Impact of Covid-19 on the Indian Economy' this liquidity shortfall and banking crises due to cash flow constraints is likely to have a 'high' impact on the sales and production of the Automobile Sector in India (Goerdeler, 2020).

Therefore, it is distinctly evident that Covid-19 has posed three primary yet gargantuan challenges for the Passenger Vehicle Sector in India - "a demand shock, an inefficient supply chain and dried up liquidity", as expressed by the Chief Financial Officers of KPMG India. 
Therefore, in order to alleviate this sector of the economy from the aforementioned adversities, arises the indispensable need for efficient, coherent policies and measures by the OEM's, Automobile Firms and Government, some of which are explored in the subsequent segment of this paper.

\section{Potential Strategies for Revitalization of the Passenger Vehicle Sector}

The Covid-19 pandemic has clearly had a devastating impact on the entire Indian Automobile Industry, this makes it imperative for economists and business analysts to devise comprehensive policies for not only the short run but the long run as well. This segment of the paper proposes certain short term and long term strategies that firms in the Automobile Industry and Indian Government can adopt in order to minimize the future economic impact of this pandemic.

\section{Potential Measures for OEMs and Automobile Companies ('Protect-Restore-Rebound' Approach)}

The 'Protect-Restore-Rebound' plan is a three stage process which includes short term policies that firms should execute quickly, as well as medium and long term plans that ensure sustainability of the industry.

\section{The 'Protect' Stage}

The 'Protect' stage i.e. the next 6 months, would primarily consist of simulation of supply chain scenarios based on the Covid-19 spread. For this, classification of dealers and suppliers on the basis of their operational and financial viability must be done by OEMs( Original Equipment Manufacturers). This would mean categorizing suppliers into 'Healthy', 'Moderate' and 'High Risk' to effectively build new supply chains. OEMs could also create support plans for High Risk dealers through various measures, such as liquidity planning, operations restart and cost reduction ideas. Further, in order to stay in touch with consumers and enhance consumer sentiment, OEMs and dealers must also devise new methods to maintain contact. Suppliers must also ensure near term working capital through current liquidity evaluations. It is also crucial for firms to prioritise customer allocations for regular payment inflow, honor contractual terms and higher demand in specific geographies. Further, OEMs and firms need to take into account the fall in production capacity and in-bound supply resulting from the limited manpower due to social distancing norms and lockdowns. Frequent engagement between suppliers and the OEMs about delays, to protect orders, and gain support would ensure there aren't any material shortages and deviations on altered parts.

The 'Restore' Stage 


\section{International Journal of Social Science and Economic Research}

ISSN: $2455-8834$

Volume: 05, Issue: 07 "July 2020"

The 'Restore' stage of this plan i.e., 6 to 12 months, primarily consists of OEMs optimizing their operations and manufacturing processes to ensure maximum efficiency is attained, thereby total operation costs are minimised. This can be achieved through various methods, OEMs and suppliers should rationalise SKUs (Stock Keeping Units) and programs, drive production and logistic efficiencies and off-load assets with low utilisation to optimise the cost structure. In addition, it is also essential for OEMs to understand and implement workforce optimisation, policy restructuring, resource reallocation (core vs. non-core) and remote working. The imposition of lockdowns worldwide has also led to an exponential rise in the overall digital usage and dependence, hence some operations of these firms can also undergo digital transformations. By developing a common digital thread for automation, monitoring, real time decisions, removal of redundancies and human intervention. Through these measures, the organization's agility and supply elasticity would rise significantly in the future.

\section{The 'Rebound' Stage}

Finally, the 'Rebound' stage i.e. post 12 months, would require OEMs and firms to create differentiated capabilities for the future in order to ensure revitalization in the long run. They should especially focus on co-creating capabilities in digital tools, such as automation, AI, ecommerce, mobility platforms, EVs and advanced safety systems. It will also be important for both OEMs and firms to allocate a right mix of new products and services portfolio taking into account the changes in consumer behaviour, including the focus on health, hygiene and connectivity needs. There also needs to be a shift in focus on the firms' end to enhancing the digital consumer experience by means of improving analytics backbone, optimising network footprint and even scaling down retail showrooms considering future consumer behaviour. Further, R\&D (Research and Development) and product teams of these companies should reassess product specification changes, wherein they should lower product and technology costs and drive increased modularity in order to enhance per unit margins, thereby making the business more sustainable in the long run. Lastly, OEMs also need to consider tracing back their global supply chains and analyzing geographical risks posed by Covid-19 when importing from badly hit states like China, North America and Europe in the long run. Instead, the domestic automobile industry would have to shift a major share of business to Indian suppliers in order to prevent any further long term disruptions in supply. Along with this, the inventory strategies for critical parts needs to be revised, primarily for ensuring sanitised and automated warehousing and logistics solutions for which additional investments from OEMs may be required. Moreover, to secure the industry from any future disturbances, firms in the Automotive Industry must increase cash reserves to tackle any long run disruptions.

\section{Potential Economic Policies for Indian Government}




\section{International Journal of Social Science and Economic Research}

ISSN: $2455-8834$

Volume: 05, Issue: 07 "July 2020"

While it is critical for private firms and OEMs to adopt appropriate measures to ensure revitalization of the Automobile Industry, true long term stability in the economy can only be attained through extensive and well executed fiscal and monetary policies implemented by the government. This section proposes, analyzes and evaluates various demand and supply side policies that the Indian Government can potentially adopt to navigate through this crisis.

\section{Short Term Policies}

Short term policies implemented by various governments to tackle the Covid-19 Pandemic include expansionary fiscal policy, easement of financial stress, and direct consumer support. Expansionary Fiscal measures primarily include reduction in direct taxes and increase in overall government spending, this essentially kick-starts domestic markets through increasing real disposable incomes of consumers and providing a monetary stimulus to the economy and more importantly increasing cash liquidity. The government should introduce flat GST rate cuts on commodities like passenger vehicles as this would increase the overall level of aggregate demand $(\mathrm{AD})$ in the economy since consumers would have greater purchasing power. In addition to that, an increase in consumer spending would boost liquidity in the economy. Furthermore, the government should even deduct income tax rates for Auto purchases, this would make it easier for consumers to acquire private vehicles which in turn would stipulate real economic growth. Government may also ensure provision of low interest loans for Passenger vehicle purchases, which would further encourage consumption by means of an indirect monetary incentive.

Additionally, the government can reduce financial stress in the automobile industry through various market-based policies. These can include direct provisions of wage subsidies to workers in the Automobile Sector, as well as direct monetary support for workers earning wages on a contractual basis who are unable to receive incomes during the extended periods of Nationwide Lockdown. The government should also consider relaxing the laws and regulations surrounding collection of direct taxes; primarily income tax, this could include allowing delayed payments of income tax, or even a reduction in interest rates charged for such late payments, at least for a few months. This would again ease off a certain amount of financial burden from a lot of consumers as well suppliers, thereby keeping the economy in control. Further, RBI (Reserve Bank of India) could also reduce interest rates, this would make it easier for consumers to take loans from commercial banks, thereby increasing purchasing power and encouraging consumption.

\section{Medium and Long Term Policies}

Along with these measures for the short run, Indian Government would also need to employ various long term policies to ensure sustained revitalization of this industry. These include reviewing old licenses, introducing repayment schemes, and revising old vehicle ownership 


\section{International Journal of Social Science and Economic Research}

ISSN: $2455-8834$

Volume: 05, Issue: 07 "July 2020"

regulations.

Firstly, there are apprehensions surrounding the renewal of licences and approvals required before initiating production or sales of automobiles, as their expiration date is approaching.

To avoid a hindrance in supply of automobiles, the government should permit OEMs and other automotive firms to continue production on their previously granted licences. Further, implementation of Repayment Support Schemes for these OEMs and firms could be of paramount help. These policies would entail government helping firms in the industry, specifically the MSMEs (Micro, Small and Medium Enterprises), through helping them repay their loan payments. Through this, debt creation is averted in the economy which could otherwise further cause a chain of financial problems in the market primarily because of the enhanced liquidity crunch by no repayment of previous loans. Lastly, another long term macroeconomic policy the government can adopt to stimulate markets, is the swift implementation of the Scrappage Policy in India. This constitutes a ruling that - any vehicle shouldn't be re-registered after it has completed a term of 15 years and hence must be scrapped at the retail outlets of these vehicles. This policy is likely to force consumption of automotives and hence boost sales in this sector as it is estimated that by mid 2020, more than 30 million vehicles would have to be removed from Indian streets under the Scrappage Policy.

\section{LIMITATIONS AND FUTURE RESEARCH DIRECTIONS}

This study harbours potential limitations. There was a severe lack of prior research regarding the Passenger Vehicle Segment of India and the economic impact of Covid-19 on this particular segment, limiting the secondary sources primarily to reports, and news articles. Furthermore, these reports and news articles merely comprised the preliminary trends in terms of the different facets of demand and supply, therefore limiting the ability of this study to suggest comprehensive and intricate long term measures for OEM's, firms and the government. In addition, as the study is based only on secondary data, demand and supply side actual behavioural intentions can only be conjectured. Studies based on primary data can be conducted to unravel actual intentions and behaviour and to predict future trends more realistically.

\section{CONCLUSION}

As India continues to endure the economic turmoil due to the COVID-19 pandemic, automobile industry of the nation is therefore set to face copious challenges. The adjudication of an impaired supply mechanism to an existant demand shock poses an amalgamation of low consumer confidence, physical limitations due to lockdowns, contracted export and import, labour shortage and a complete collapse of production to the near-stagnant Passenger Vehicle Sector of India, 
International Journal of Social Science and Economic Research

ISSN: $2455-8834$

Volume: 05, Issue: 07 "July 2020"

rendering the compelling need for an astute plan of revitalization. As explored in the prior segments of this study, the alleviation of the Passenger Vehicle Sector from this vicissitude can only be accomplished through distinct, comprehensive measures. These encompass the adoption of a 'Protect-Restore-Rebound' plan by private firms, which effectively requires OEMs to simulate supply chains, optimise their production process and create long run differentiated capabilities, in that specific order to ensure sustained growth, always keeping in mind future prospects of business. Similarly, the government must focus on Expansionary Fiscal policies, easement of financial stress and direct consumer support in the short run. Whereas, in the long run certain market based policies specific to the Automobile sector need effective implementation, primarily the review of laws surrounding Supplier Licences, provision of Repayment Support schemes and the revision of regulations for Old Vehicle Ownership. If the private sector and the government execute an integrated, perceptive and far seeing response, complete revitalization from this ruinous predicament, while still challenging, would become significantly easier to attain.

\section{REFERENCES}

Society of Indian Automobile Manufacturers. (n.d.). Retrieved from http://www.siam.in/ Accessed 10th June, 2020.

Reserve Bank of India. (April, 2020). Consumer Confidence Survey 2020 (pp. 1-7). Accessed from

https://m.rbi.org.in/Scripts/QuarterlyPublications.aspx?head=Consumer\%20Confidence \%20Survey on 12th June, 2020.

Marwick Goerdeler, K. P. (April, 2020). Potential Impact of Covid on the Economy (April 2020, pp. 17-18). KPMG report.

Brooks, L., \& Sabet, A. (May, 2020). Five critical uncertainties facing the steel raw materials market due to Covid-19 (pp. 1-3). Commodities Research Unit.

K, S. (2020). Covid-19 Impact - Business Leaders' view on impact of Covid on the Economy as well as their Businesses (pp. 8-16). Feedback .

Mukhtyar, K., \& Chatterjee,, S. (2020). Oem Market Performance FY2020 (pp. 6-9). PricewaterhouseCoopers.

Price water house Coopers. (2020). Covid-19 Crisis - Impact on the automotive industry navigating the turbulence (April 2020, pp. 3-39). 


\section{International Journal of Social Science and Economic Research}

ISSN: $2455-8834$

Volume: 05, Issue: 07 "July 2020"

Sengupta, R., \& Dev, S. M. (2020). Covid-19: Impact on the Indian Economy Indira Gandhi Institute of Development Research, Mumbai.

Accenture. (2020). How Covid-19 will permanently change consumer behavior Fast-changing consumer behaviors influence the future of the Cpg industry (April 2020, pp. 1-34).

Roland Berger. (2020). Covid-19 Impact and Priorities for automotive companies (March, pp.427).

Collie , B. (2020). Covid-19 Automotive demand post Covid-19 (April 2020, pp. 13-20). Boston Consulting Group.

Beredo, C. (2020). Impacts to Automotive Supply Chains From Covid-19 (April 2020, pp. 1-2). Squire Patton Boggs.

Autobei Consulting Group (July, 2019). Indian Automobile Industry Report Q1 Fy 2020. Accessed from

https://www.autobei.com/autoreports/automotive/indian-automobile-industry-report-q1-f y-2020/\#: :text=We\%20have\%20released\%20the\%20Indian\%20Automobile\%20Industr y\%20Report\%20Q1\%20FY\%202020\%20report.\&text=In\%20the\%20first\%20quarter\%2 0of,to\%20a\%20mere\%2018\%20percent on 15th June, 2020.

Kumar, A. (May 9,2020). The Pandemic is Changing the Face of Indian Labour. The Wire. Retrieved from https://thewire.in/economy/covid-19-pandemic-indian-labour on 15th June, 2020.

COVID-19: Supply chain shock will have a negative impact on domestic auto component industry. (2020, April 3). Auto Economic Times . Retrieved from https://auto.economictimes.indiatimes.com/news/auto-components/covid-19-supply-chai n-shock-will-have-a-negative-impact-on-domestic-auto-component-industry/74967722 on 14th June, 2020.

COVID-19 may force the automotive sector into less reliance on contract labour: Report. (May 10, 2020). The New India Express. Retrieved from https://www.newindianexpress.com/business/2020/may/10/covid-19-may-force-automoti ve-sector-into-less-reliance-on-contract-labour-report-2141524.html on 13th June, 2020.

Automakers in India halt production. (March 24,2020). The Automotive News Europe . Retrieved from https://europe.autonews.com/automakers/automakers-india-halt- 
International Journal of Social Science and Economic Research

ISSN: 2455-8834

Volume: 05, Issue: 07 "July 2020"

production Accessed on 14th June, 2020.

Coronavirus supply chain shock will have a negative impact on Indian auto component sector .

The Economic trimes. $\quad$ Retrieved from https://economictimes.indiatimes.com/industry/auto/auto-components/coronavirus-supply -chain-shock-will-have-negative-impact-on-indian-auto-component-sector/articleshow/74 966259.cms?from=mdr Accessed 13th June, 2020.

Impact of COVID-19 On The Automotive Manufacturing Supply Chain. (n.d.). Asia Pacific Metal Working Equipment News. Retrieved fromhttps://www.equipment-news.com/impact-ofcovid-19-on-the-automotive-manufacturing-supply-chain/ on 16th June, 2020.

Exports plunge by record 60.28\% in April; trade deficit lowest in 4 years (May 15, 2020). The Economic Times. Retrieved from https://economictimes.indiatimes.com/news/economy/foreign-trade/covid-19-impact-exp orts-plunge-60-28-pc-in-april/articleshow/75760239.cms?from=mdr on 13th June, 2020.

"Domestic passenger vehicle sales plunge 51\% in March hit by " (13 Apr. 2020), The Times of India. Retrieved from

https://timesofindia.indiatimes.com/business/india-business/domestic-passenger-vehiclesales-plunge-51-in-march-hit-by-coronavirus-pandemic-siam/articleshow/75121411.cms. on 12th June, 2020.

"Impact of coronavirus on car market: ETAuto Originals: COVID " (18 May, 2020). The Economic Times, Retrieved from https://auto.economictimes.indiatimes.com/news/passenger-vehicle/cars/etauto-originalscovid-19-to-change-fate-of-indian-car-market/75283843. on 17 June, 2020. 